\title{
JOVENS, CIÊnCIA E MEDIA: PERCEÇÕES SOBRE A ASTRONOMIA E CIÊNCIAS DO ESPAÇO EM CONTEXTOS FORMAIS E INFORMAIS
}

\author{
Sara Anjos \\ Centro de Estudos de Comunicação e Sociedade, Instituto de Ciências Sociais, Uni- \\ versidade do Minho, Portugal / Universidade de Leiden, Países Baixos
}

Anabela Carvalho

Centro de Estudos de Comunicação e Sociedade, Instituto de Ciências Sociais, Universidade do Minho, Portugal

\begin{abstract}
Resumo
O papel transversal dos media na aquisição de conhecimentos e na formação de opiniões e representações de assuntos de ciência tem uma importância reconhecida. Porém, existem poucos estudos que se debrucem sobre o modo como os jovens acedem, compreendem e criam conteúdos relacionados com a ciência, utilizando diversas plataformas e acionando diferentes literacias. O presente estudo procura explorar algumas pontes nesse sentido. Tendo como base públicos jovens interessados em ciência, nomeadamente em Astronomia e Ciências do Espaç̧o, o estudo pretende averiguar o que estes valorizam na ciência e como se apropriam da informação científica para a tomada de decisão e a formação de opiniões sobre ciência. Os resultados confirmam que as aprendizagens informais têm um papel relevante no desenvolvimento de uma identificação com a ciência e na escolha por percursos académicos e profissionais com ela relacionados. Apesar de não procurarem notícias de ciência em geral, pesquisam informação específica de ciência de acordo com os seus interesses. A ausência de uma reflexão sobre como os discursos e as notícias de ciência são produzidos e filtrados pelos media e outros agentes de comunicação de ciência faz ressaltar a relevância da promoção de uma literacia crítica de ciência, que implica a ligação a outras literacias, incluindo a literacia mediática.
\end{abstract}

\section{YOUTH, SCIENCE, AND MEDIA: PERCEPTIONS OF ASTRONOMY AND SPACE SCIENCES IN FORMAL AND INFORMAL CONTEXTS}

\begin{abstract}
The importance of the media, both in the acquisition of knowledge, and in the formation of opinions and representations of science subjects, has been widely acknowledged in research. However, there is still an insufficient number of studies which focus on how young audiences specifically access, understand and create science-related content via different platforms, thereby mobilising different literacies. The present empirical study seeks to explore some bridges in this regard. By looking at a young public interested in science, namely Astronomy and Space Sciences, we intend to ascertain what they value and how they appropriate scientific information in their social relations in order to build critical scientific literacy for decision-making and the formation of opinions about science. The main results of this study confirm that informal learning plays an important role not only in the development of identification with science by young people,
\end{abstract}


but also in the search for related academic and professional pathways. Although it confirms that younger people do not seek science news, the current study suggests that they do engage in seeking science-specific information according to their interests. The absence of a reflection on how science discourses and news are produced and filtered by the media and other science communication agents underlines the relevance of promoting critical science literacy, which seems to imply a link to other literacies, media literacy included.

\section{INTRODUÇÃo}

Embora os media tenham um papel importante na formação da identidade dos mais novos (Buckingham, 2008; Davies \& Horst, 2016; Dover, 2007; Nelms, Allen, Craig \& Riggs, 2017), a sua influência na construção de uma literacia crítica de ciência e na formação de aspetos da identidade que se relacionam com (assuntos de) ciência por jovens tem sido pouco explorada. Ainda são parcos os conhecimentos sobre os seus hábitos de consumo de informação científica, nomeadamente em atividades de comunicação de ciência em contextos informais (em centros de ciência e nos media, por exemplo) e a influência que podem ter no desenvolvimento da literacia científica.

Vários estudos sugerem que os níveis de educação escolar e os media têm um papel na relação que os públicos constroem com a ciência, nomeadamente na participação em assuntos com ela relacionados ao longo da vida (Besley \& Nisbet, 2013; Brossard \& Scheufele, 2013; Peters et al., 2008; Suerdem, Bauer, Howard \& Ruby, 2013). Dada a constante presença da ciência nos media, de forma explícita ou indireta, e a importância da tomada de decisões baseada em investigação científica, a capacidade de analisar criticamente informação científica veiculada pelos media é vista por muitos académicos como um relevante indicador da literacia científica (DeBoer, 2000; Jarman \& McClune, 2010; Korpan, Bisanz, Bisanz \& Henderson, 1997; Norris, Phillips \& Korpan, 2003). Porém, estudos com vista a medir a literacia científica dos mais novos (e.g. Norris et al., 2003) focam-se mais na compreensão de factos e conhecimentos de ciência nas notícias, do que nos modos como os seus constructos e atores são representados nos diferentes media, influenciando as perceções da ciência e dos cientistas que vão sendo construídas.

Apesar de existirem evidências de que os media influenciam na criação da identidade cultural dos jovens (Rahim \& Pawanteh, 2009; Tőrők-Ágoston, 2017), falta analisar implicações na formação de opiniões e na tomada de decisões relacionadas com a ciência, como a aspiração e opção por uma carreira científica. Diversos relatórios (e.g. Cardoso, Mendonça, Paisana \& Lima, 2016) atestam que os mais novos utilizam múltiplos dispositivos de acesso à informação (telemóveis, tablet e computadores, além da televisão) e que privilegiam as redes sociais para aceder a conteúdos de entretenimento e de pesquisa e partilha de informação. Parte desta informação poderá ser sobre ciência, 
com um peso importante na interceção entre as aprendizagens formais e informais dos mais novos (Halkia \& Mantzouridis, 2005).

O papel dos media, e em particular dos media digitais, não deve continuar a ser ignorado no conhecimento e nas competências que os mais novos desenvolvem (Pereira, Fillol \& Moura, 2019), incluindo o que os jovens vão formando sobre a ciência e os cientistas (Tang, 2013; Tang \& Moje, 2010). Se nas sociedades de conhecimento a aprendizagem de factos científicos ocorre por exposição espontânea em diversos contextos (Falk, Storksdieck \& Dierking, 2007), e sobretudo para os jovens esta aprendizagem é permeada por uma forte presença dos media nos seus quotidianos, faz sentido procurar relações sobre a contribuição dos media para a construção da sua literacia científica. Por isso as inter-relações entre as diversas literacias que os mais jovens vão construindo, incluindo a literacia mediática e a literacia científica, merecem uma análise crítica continuada da parte dos cientistas sociais, fazendo confluir os estudos de comunicação e os de ciência-tecnologia-sociedade (Boczkowski, 2007).

Este estudo visa estabelecer pontes nesse sentido, tendo como referência públicos jovens interessados em ciência, nomeadamente Astronomia e Ciências do Espaço. Procura averiguar o que esses jovens valorizam na ciência, como se apropriam da informação científica a que acedem por diferentes meios e que usos fazem dela nas suas relações sociais. Neste sentido, pretende responder às seguintes questões:

- Que plataformas e meios privilegiam os públicos mais novos para aceder a conteúdos relacionados com ciência?

- Como agem os jovens em relação à partilha e ao diálogo sobre assuntos de ciência com a família, os amigos e, eventualmente, na escola e nos media?

- Que representações e aspirações estes públicos evidenciam em relação à ciência e aos cientistas do Espaço?

O artigo parte de considerações teóricas sobre as representações da ciência nos media e sobre o seu papel na formação da identidade dos jovens, articulando com a construção da literacia científica em contextos formais e informais. Depois de contextualizar o estudo e analisar os dados recolhidos, termina com reflexões sobre a necessidade de dar voz aos públicos mais novos, promovendo a sua capacitação, agência e envolvimento na criação de espaços, formais e informais, para a promoção do diálogo e da participação entre a ciência e a sociedade, com recurso a diferentes literacias.

\section{OS JOVENS, A CIÊNCIA E OS MEDIA: CULTURA, IDENTIDADE E LITERACIA CRÍTICA DE CIÊNCIA}

Não podemos ignorar a importância dos media na vida social, económica e cultural nas sociedades de hoje. Os discursos mediados e os artefactos tecnológicos que os assistem estão presentes no quotidiano das chamadas sociedades do conhecimento de uma forma tão indelével que por vezes se dilui noutros contextos de interação, sendo difícil isolar os seus efeitos em aspetos concretos da vivência das pessoas. Torna-se difícil negar que estes meios, ferramentas e redes digitais levam a diversas formas de aprendizagem e aquisição de competências (Buckingham, 2008; Pereira et al., 2019). 
Para Buckingham (2008) são aprendizagens que se refletem em expressões de identidade e na capacidade dos indivíduos formarem opiniões de forma independente e criativa.

Estas expressões sociais e culturais da identidade assumem particular importância para os mais jovens, à medida que vão efetuando tomadas de posição e decisões que podem influenciar escolhas futuras em termos de opções profissionais, de relacionamentos e de modos de vida. Os recursos simbólicos que encontram e que utilizam para construir, expressar ou decifrar as suas próprias identidades, ou as dos outros, passam pelo uso dos media (Mendick \& Moreau, 2013). Porque o conteúdo nos media não é neutro, a literacia mediática deve ir além de aprendizagens funcionais, para levar em conta a capacidade de avaliar informação de forma crítica, procurando perceber as representações simbólicas, os seus efeitos sociais, as intenções de quem produz conteúdos mediáticos, entre outros aspetos (Boczkowski, 2007; Buckingham, 2008).

Por sua vez, a construção de uma literacia científica implica chamar a si diversos contextos de aprendizagem e diferentes modos de pensar e de atuar face à ciência, olhando para ela de uma forma crítica (Carvalho, 2004; Priest, 2013). É esta a perspetiva que concebemos para uma literacia crítica de ciência, isto é, as capacidades para compreender motivações, valores, símbolos e relações de poder subjacentes ao discurso científico (nos seus múltiplos modos - verbal, imagético e outros), os contextos de produção e funcionamento social da ciência, e as suas implicações sociais, económicas e políticas (Gregory \& Cahill, 2009; Jarman \& McClune, 2010)1993.

Tanto os mass media como os media digitais são uma fonte primária de informação relacionada com questões científicas (Brossard \& Scheufele, 2013; Bubela et al., 2009; Gerhards \& Schäfer, 2009). Ao ter evoluído nos seus processos e práticas, a ciência tornou-se mais aberta e dependente de colaborações globais e interdisciplinares e de financiamento privado. Passou também a adotar práticas de comunicação em linha com as de outras organizações e empresas, recorrendo ao marketing e relações públicas, assim como a práticas e lógicas dos media (Bauer, 2008; Bucchi \& Trench, 2014; Entradas, 2015). Os assuntos científicos foram multiplicados nesse ambiente virtual, não deixando dúvidas sobre o papel dos media na construção de narrativas relacionadas com a ciência, refletindo preocupações do público e afetando as suas perceções (Feinstein, 2015). Este uso generalizado dos media exige que se pense neles como mais do que "canais de informação científica" (Bucchi \& Trench, 2014, p. 9). Para uma literacia científica num ambiente onde nem sempre é clara a distinção entre "entretenimento, promoção, informação, notícias e publicidade" (Priest, 2013, p. 140), não é suficiente a aquisição cognitiva de informação científica; importa uma perspetiva crítica para avaliar os contextos em que os discursos de ciência são criados.

Deste modo, a literacia científica relaciona-se com capacidades e conhecimentos que o indivíduo deve ser capaz de construir ao longo da vida (Falk, Storksdieck \& Dierking, 2007), e que incluem a reflexão sobre as ações e intenções de diversos agentes intervenientes, reconhecendo que todas as informações passam por uma "filtragem" (Hofstein, Eilks \& Bybee, 2011, p. 1466). Enquanto Feinstein (2011) questiona o papel da escola na preparação dos seus alunos para debates relacionados com temas de ciência, 
nos media e em outros contextos da vida quotidiana, outros académicos destacam a capacidade de analisar criticamente informação científica veiculada nos media como uma meta importante no ensino formal (Jarman \& McClune, 2010). As lógicas de mediação e de "filtragem" devem ser identificadas na maneira como a ciência é comunicada, reconhecendo que o público é um utilizador social ativo e reconstrutor de significados relacionados com a ciência (Cope \& Kalantzis, 2009).

Considerando que a literacia mediática se expressa na capacidade de aceder, compreender e criar comunicações em diversos contextos (Buckingham, Banaji, Carr, Cranmer \& Willett, 2005), importa perceber como pode ser considerada quando o contexto se relaciona com assuntos de ciência e qual o papel dos media no desenvolvimento da literacia científica e na promoção da identidade cultural relacionada com ciência. Numa perspetiva de literacia crítica (Gainer, 2010; Kellner \& Share, 2007), os estudantes são incentivados a analisar a relação entre os media, as audiências, a informação e o poder, para depois produzirem alternativas ao discurso dominante, que tende a perpetuar desigualdades (de género, raciais e outras).

Estes aspetos merecem especial destaque em assuntos de ciência, uma vez que as mulheres, as classes sociais menos privilegiadas e alguns grupos étnicos minoritários estão pouco representados nas carreiras de ciência e tecnologia, especialmente nas ciências físicas e nas engenharias (DeWitt et al., 2013). A ligação entre ciência, poder e o papel masculino foi identificada como obstáculo para alguns grupos desfavorecidos (DeWitt \& Bultitude, 2018; Lane, Goh \& Driver-Linn, 2012; Miller, Eagly \& Linn, 2015). A literacia mediática poderá ter aqui um importante papel, quer pelo potencial de capacitar a avaliação crítica das imagens da ciência perpetuadas nos media, como pela possibilidade de capacitar a construção de narrativas de ciência que levam em conta contextos e constrangimentos em que aquela é feita, desconstruindo discursos de poder e possibilitando um olhar crítico às múltiplas dimensões da construção do conhecimento.

\section{O CONTEXTO: UMA ATIVIDADE DE COMUNICAÇÃO INFORMAL DE CIÊNCIA}

A Universidade Júnior ${ }^{\prime}(U J)$ serviu de contexto para auscultar jovens estudantes do ensino não superior. Os dados foram recolhidos durante o programa de verão "Astronomia: dos conceitos à prática" 2 , oferecido pelo Centro de Astrofísica da Universidade do Porto (CAUP) e pelo Planetário do Porto em julho de 2019.

A iniciativa "Verão em projeto" tem uma abrangência nacional e é promovida pela Universidade do Porto no âmbito da Universidade Júnior, sendo procurada como ocupação de férias para crianças e jovens do $5^{\circ}$ ano ao $11^{\circ}$ ano de escolaridade. Implementada desde 2005 , a iniciativa tem uma procura muito elevada, com cerca de 6.000 vagas na edição de 2019. Inclui atividades promovidas por diferentes unidades orgânicas da instituição, desde faculdades a centros de investigação, que adequam a sua oferta ao

\footnotetext{
Para mais informações sobre a iniciativa visitar https://universidadejunior.up.pt/programas. php?p=verao-em-projeto-9-10-e-11

${ }^{2}$ Retirado de https://universidadejunior.up.pt/atividades.php?a=astronomia-dos-conceitos-a-pratica
} 
público de acordo com a sua idade e propósito do programa. Crianças e jovens têm a oportunidade de conhecer diferentes espaços da Universidade e participar em projetos e atividades variadas, desde práticas laboratoriais, trabalhos de campo, visitas de estudo, trabalhos de grupo, entre outros. Os participantes selecionam entre os diferentes programas aquele ou aqueles que melhor se ajustam aos seus interesses. Em 2019, como noutros anos, foi oferecida uma atividade específica relacionada com a Astronomia destinada a jovens do $9^{\circ}$ ao $11^{\circ}$ ano.

\section{ASTRONOMIA: DOS CONCEITOS À PRÁTICA}

A atividade promovida pelo CAUP, "Astronomia: dos conceitos à prática", foi realizada em duas semanas de julho (8-12 de julho e 15-19 de julho de 2019) e envolveu dois grupos de 20 participantes cada. O seu objetivo: "que os participantes fiquem a saber um pouco mais sobre o Universo que nos rodeia" 3 . Em cada semana, os jovens puderam participar em aulas (sobre estrelas, galáxias, cosmologia, exoplanetas, telescópios, como fazer uma apresentação), laboratórios práticos (sobre meteoritos, exoplanetas, impressão), sessões de planetário e numa sessão de conversa com os investigadores. A Tabela 1 caracteriza cada grupo de participantes.

\begin{tabular}{cccc}
\hline & & SEmaNa 1 & SEMANA 2 \\
\hline \multirow{2}{*}{ Género } & Feminino & 13 & 9 \\
\cline { 2 - 4 } & Masculino & 7 & 11 \\
\hline \multirow{3}{*}{ Ano escolar frequentado em 2018/2019 } & $9^{\circ}$ & 6 & 11 \\
\cline { 2 - 4 } & $10^{\circ}$ & 11 & 7 \\
\cline { 2 - 4 } & $11^{\circ}$ & 3 & 2 \\
\hline
\end{tabular}

Tabela 1: Perfil dos participantes

Neste evento foi possível caracterizar os participantes quanto a: 1) motivações associadas à frequência de uma ação deste género; 2) plataformas e meios que utilizam para aceder a informação e conhecimentos de Astronomia; e 3) atitudes e comportamentos em relação à partilha e ao diálogo sobre assuntos de Astronomia com a família, os amigos e, eventualmente, na escola e nos media. Procuramos aspetos que associamos à literacia crítica de ciência e a sua relação com outras literacias.

\section{Metodologia}

A combinação de metodologias apresentou-se como uma escolha apropriada para este estudo, num paradigma de investigação crítico e emancipatório. Foram usadas diferentes metodologias de recolha e de tratamento de dados (quantitativos e qualitativos), por serem complementares, tendo cada uma potencialidades e limitações específicas.

\footnotetext{
${ }^{3}$ Retirado de https://universidadejunior.up.pt/atividades.php?a=astronomia-dos-conceitos-a-pratica
} 
Assim, recolhemos informação recorrendo a metodologias mistas: inquéritos por questionário online; discussão em grupo; grupos focais e observação participante, com recurso a um diário de campo. Os dados recolhidos em áudio cumprem as normas éticas e do Regulamento Geral de Proteção de Dados (RGPD) ${ }^{4}$.

Os jovens que auscultamos no âmbito da atividade "Verão em projeto" não serão representativos dos jovens "em geral". Sabendo que existem reconhecidas desigualdades no acesso à ciência, os seus participantes provêm, muito provavelmente, de contextos socioeconómicos mais favorecidos e as suas opiniões sobre ciência serão influenciadas por este contexto. Contudo, o manifesto interesse pela ciência e pela frequência de uma atividade informal com ela relacionada torna-os num grupo de particular relevância para os objetivos desta pesquisa.

\section{DESCRIÇÃo}

O estudo exploratório permitiu auscultar jovens entre 14 e 18 anos quanto à sua relação com a ciência em espaços de carácter informal. Em Portugal, é por volta dos 14 e 15 anos que os alunos fazem opções quanto ao futuro percurso de nível secundário, escoIhendo entre cursos científico-humanísticos, cursos artísticos especializados ou cursos profissionais. Perspetiva-se nesta fase que as preferências, atitudes e opiniões quanto à ciência estejam estabelecidas a um nível suficiente para poderem tomar esta decisão. Portanto, os jovens que frequentaram este programa em concreto manifestavam interesse nomeadamente em Física, Astronomia e Ciências do Espaço e equacionariam seguir alguma destas áreas como opção académica e profissional no futuro.

Para melhor compreender a relação que os participantes nesta atividade desenvolvem com a ciência e a contribuição dos media nessa relação, coletaram-se dados junto dos dois grupos de 20 participantes.

Depois de se ter dado a conhecer o estudo e confirmado o consentimento informado, num primeiro momento coletou-se informação com recurso a um diário de campo, incidindo na atividade "conversa com os investigadores". De seguida realizou-se um inquérito por questionário a todos os participantes em cada semana, com simultânea discussão em grupo dos seus resultados. Para o efeito, recorremos a um software informático, Wooclap5, que destaca e exibe em grande ecrã as frequências relativas das respostas dadas a cada questão. Portanto produziram-se e coletaram-se também dados qualitativos, pois essas respostas complementadas pela discussão em grupo permitiram aferir o porquê das opções tomadas e também esclarecer questões não previstas num questionário fechado. Deste modo, procuramos perceber ideias, atitudes, opiniões e vivências dos jovens que se relacionam com a ciência e com a atividade que frequentaram nessa semana.

Complementarmente, realizaram-se seis grupos focais (três em cada semana), com seis a oito participantes. Cada grupo foi confrontado com questões relacionadas

\footnotetext{
${ }^{4} \mathrm{~A}$ informação aos pais foi agregada às demais autorizações requeridas pela $\mathrm{UJ}$.

${ }^{5}$ Informações disponíveis em https://www.wooclap.com/
} 
com os objetivos patentes na Tabela $2^{6}$, ajustadas às intervenções dos participantes. As discussões variaram entre os 35 e os 55 minutos e foram gravadas em áudio.

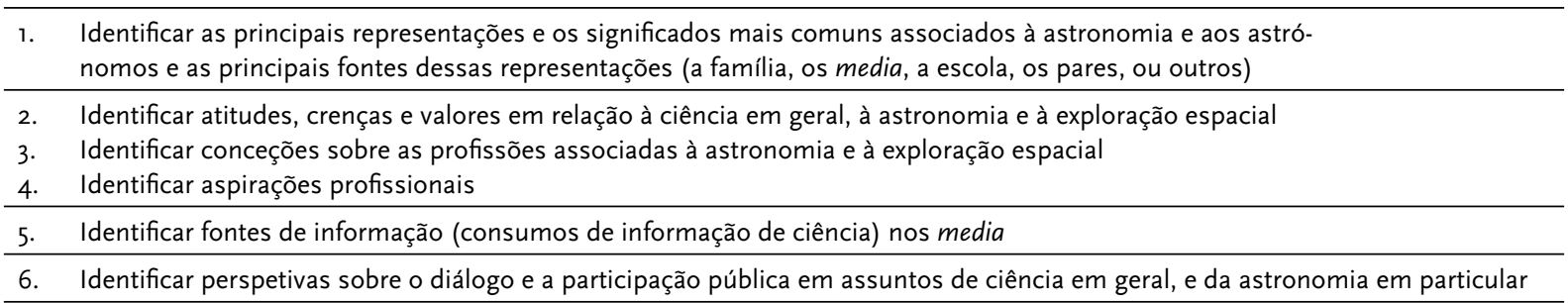

Tabela 2: Objetivos específicos da recolha de dados através do questionário e do guião dos grupos focais

Depois da transcrição e da familiarização com os dados através de múltiplas leituras, analisamos a informação procurando temas com base num paradigma construtivista de interpretação de significados. $\mathrm{Na}$ análise temática tivemos em conta os objetivos do estudo, os temas presentes nas falas dos participantes e os assuntos abordados nos grupos de discussão. Apresentamos de seguida a análise sobre motivações, aspirações profissionais, representações e consumos de media no que respeita a assuntos de ciência.

\section{ANÁLISE dos DADOS}

Tendo os jovens participantes expressado por vários meios o modo como percecionam as suas motivações, atitudes e comportamentos em relação à Astronomia, apresentamos de seguida algumas considerações que envolvem pontes com os media e a escola.

\section{CONSUMOS DE MEDIA E PARTILHA DE INFORMAÇÃo}

Fontes de informação de ciência: os questionários revelaram que os participantes raramente procuram e/ou acedem a informação de ciência nos media convencionais e a maioria nunca ou quase nunca partilha ou comenta essa informação. Quando o fazem, dois terços privilegiam um motor de busca e a visita a sites institucionais de referência na área - os da National Aeronautics and Space Administration (NASA) e da European Space Agency (ESA) foram os mais referidos. Todos disseram usar redes sociais e alguns seguem páginas de instituições e canais no YouTube que publicam regularmente informação e conteúdos sobre ciência.

\footnotetext{
${ }^{6}$ Para além dos objetivos indicados neste artigo, o estudo procurava ainda: 1) identificar motivações para frequentar as ações de comunicação de ciência e contextos associados; 2) identificar o que estes públicos conhecem e valorizam sobre as descobertas e aplicações científicas de astronomia no seu quotidiano; 3) identificar preferências quanto à forma e conteúdo das ações de comunicação de ciência; 4) analisar a autoavaliação dos seus conhecimentos de astronomia e dos processos de produção de conhecimento (forma de fazer ciência); 5) identificar mudanças ocorridas nos aspetos acima enunciados atribuídas à frequência de uma ação de comunicação de astronomia.
} 
Se a informação for do seu interesse, estes jovens investem na procura de mais informação usando um motor de busca e selecionando sites fidedignos. Não procuram notícias de ciência em geral, mas pesquisam informação de ciência sobre temas do seu interesse e este interesse pode até ter surgido através de uma notícia que viram no seu feed de notícias nas redes sociais. Assim, destaca-se a sua iniciativa em seguir instituições nas redes sociais, como a NASA e a ESA, que publicam notícias e informação sobre ciência. Muitas vezes estas publicações servem de mote para pesquisar informação adicional sobre o tema, utilizando o motor de busca (habitualmente o Google) ou seguindo as ligações nelas sugeridas.

Eu acho que por exemplo uma pessoa que siga a NASA no Instagram à partida procurou pela informação, não é? Porque se seguiu é porque está interessada. (Participante do sexo feminino, $10^{\circ}$ ano, grupo focal 6 )

Nos grupos focais, os participantes tenderam a concordar com a seguinte afirmação:

a maioria dos utilizadores mais novos obtém notícias nos seus dispositivos móveis como resultado de estarem em plataformas como Facebook ou Twitter. Eles encontram as notícias, em vez de procurarem por elas. Fazem isto como resultado de viverem nos media, em vez de usarem os media. (Boczkowski, Mitchelstein \& Matassi, 2017, p. 1785)

$\mathrm{Sim}, \operatorname{sim}$, sim, uma pessoa segue alguma coisa e depois encontra alguma informação. Para saber mais temos de procurar, mas nós encontramos a informação, não vamos à procura dela. (Participante do sexo masculino, $9^{\circ}$ ano, grupo focal 5)

Eu acho que isso [seguir sites institucionais de ciência] traz vantagens e desvantagens porque podem aparecer notícias que são do nosso interesse, mas que nós nunca procuraríamos especificamente essa notícia e nós seguimos coisas que têm assuntos que nós gostamos e aparecem as notícias, depois claro podemos pesquisar e assim, mas é uma vantagem. (Participante do sexo feminino, $9^{\circ}$ ano, grupo focal 5 )

Apesar de referirem não procurar notícias de ciência nos media, os participantes mostraram estar informados quanto às notícias mais destacadas na imprensa - reconheceram a fotografia do buraco negro captada pela equipa internacional Event Horizon Telescope (EHT), por exemplo, que pouco tempo antes da realização deste estudo tinha tido uma forte presença nos media convencionais. Este encontro casual de notícias de ciência nas redes sociais parece ser satisfatório na tomada de consciência de notícias de ciência de grande cobertura pelos media.

A procura por sites fidedignos e informação rigorosa foi frequentemente referida. Os participantes salientaram que a escola falha na capacitação para a procura de informação de ciência em plataformas digitais e para o debate e a tomada de decisões sobre 
assuntos de ciência. Para eles, na disciplina de Cidadania e Desenvolvimento poderiam aprender mais sobre isso, pela importância que tem no "aprender a ser cidadão" (participante do sexo masculino, $9^{\circ}$ ano, grupo focal 6 ).

Sim, a escola é o ponto de partida para nós sermos cidadãos, então nós devíamos aprender tudo, ou seja, aprender isso é muito importante que nós podermos tomar uma decisão e fazer uma mudança em alguma coisa e pelo menos o podermos fazer informadamente (sic). (Participante do sexo feminino, $9^{\circ}$ ano, grupo focal 5 )

Para estes jovens, serão as instituições a conferir credibilidade à informação encontrada, pois quando questionados sobre os critérios utilizados para descortinar se uma notícia de ciência é credível ou não, remetem para nomes de pessoas ou de instituições mais populares no meio científico (como sites da NASA). Contudo, admitem que nem sempre é fácil aferir a credibilidade da informação de ciência e referem que deveriam aprender na escola a diferenciar informação fiável da demais informação:

claro, há sites que vê-se logo, mas há outros que não, que têm informação errada ou desatualizada. Por isso achava ser importante saber como procurar informação. (Participante do sexo feminino, $9^{\circ}$ ano, grupo focal 5 )

No que respeita a informação e conhecimentos de ciência, as discussões nos grupos focais revelaram tendências de consumo recorrendo aos media. Os interessados pela área destacaram a leitura de livros (os de Stephen Hawking foram referidos várias vezes), a visualização de séries (sobretudo a série Cosmos), documentários e apresentações (principalmente do National Geographic ou TedTalk). A leitura de livros e o consumo de séries parecem relevantes na descoberta e na afirmação de uma postura que pende para a adoção de uma identidade profissional relacionada com a ciência (físico e astrónomo, neste caso). De facto, todos os participantes com interesse manifesto na área partilhavam os seguintes consumos de media: nas redes sociais (sobretudo no Instagram) seguiam páginas de instituições relacionadas com o espaço, como as da NASA, ESA e European Southern Observatory (ESO); liam livros de divulgação de ciência relacionados com a Física ou Astronomia; viam séries e documentários na televisão ou no YouTube. Estes jovens procuravam aspetos com os quais sentiam uma identificação quer com os restantes participantes quer com os investigadores com quem contactaram, como ilustra o seguinte excerto:

queria dizer também que nas conversas com os investigadores houve um que me incentivou bastante porque eu realmente gosto bastante de Física e quando houve um a dizer que desde que leu o livro de Stephen Hawking passou a gostar de Física realmente fez-me pensar -"foi uma situação parecida com a minha" - li os livros de Stephen Hawking e é daí que vem o meu interesse por esta área. (Participante do sexo masculino, $10^{\circ}$ ano, grupo focal 3) 
Relativamente à criação de conteúdos, os participantes falaram na realização e apresentação de trabalhos para fins escolares. Afirmaram que os agentes educativos assumem que os jovens sabem efetuar pesquisas na internet e selecionar informação, não havendo preocupação em ensinar a fazê-lo, seja para assuntos de ciência ou outros. Referiram ainda que tinham pouco apoio da escola para iniciativas que fossem de encontro aos seus interesses de ciência, como palestras, debates e outros eventos, considerando-os importantes para se ser cidadão.

\section{MOTIVAÇõES, REPRESENTAÇõ̃S E ASPIRAÇõES PROFISSIONAIS}

Cerca de metade dos participantes (59\% na semana $1 ; 39 \%$ na semana 2 ) afirmaram ter interesse em Astronomia e Ciências do Espaço, ponderando seguir esta área ou outra relacionada, pelo que frequentaram a ação como forma de confirmar a intenção, a fim de perceber melhor o que faz um astrónomo e entrar em contacto com as matérias que perspetivam estudar na universidade. Para os mais indecisos, esta ação permitiria eliminar possibilidades quanto a opções académicas ou profissionais. Outros estavam curiosos para conhecer um pouco mais sobre Astronomia, optando por ocupar o seu tempo livre nas férias seguindo a sugestão de pais ou amigos.

Não percebemos diferenças de género quanto às aspirações destes jovens em relação à Física ou Astronomia. De facto, tanto rapazes como raparigas admitiram o seu interesse na área. Apesar de considerarem não existirem diferenças de género assinaláveis no acesso à profissão de astrónomo (nos questionários a grande maioria discordou da afirmação: "cientistas do espaço normalmente são homens"), quando discutiam sobre cientistas que conheciam, autores de livros na área ou séries e documentários que acompanhavam, referiram apenas homens (Stephen Hawking, Neil deGrasse Tyson, Carl Sagan, Michio Kaku). Uma das participantes referiu:

há mais astrónomos homens do que mulheres mas tem mais a ver com o facto de que (...) a educação informal que as mulheres recebem é um bocado diferente do que os homens recebem e portanto as mulheres estão normalmente menos ligadas a áreas como Astronomia do que os homens, de uma maneira informal, por exemplo em brinquedos, ou em séries ou em... no mundo informal os homens são desde cedo mais ligados a áreas de ciência e para tecnologia e coisas do género do que as mulheres e portanto isso vê-se nos na percentagem de mulheres que existem como ligadas a Astronomia, é o que eu acho. (11 ${ }^{\circ}$ ano, grupo de discussão do questionário na semana 1 )

Embora assumindo não ter estereótipos quanto à representação do que é ser astrónomo, salientaram que os estereótipos existem na sociedade, sobretudo para pessoas mais velhas, ao considerar-se o astrónomo como uma "pessoa fechada, antissocial, focada nos cálculos, que não tem muita capacidade de falar com as pessoas, sim que está muito focada na sua área" (participante do sexo feminino, $9^{\circ}$ ano, grupo focal 
5). As pessoas "mais jovens já têm a noção que não é assim, os mais antigos é que veem assim" (participante do sexo masculino, $9^{\circ}$ ano, grupo focal 5).

Para desfazer estereótipos sugerem que o facto de contactar com profissionais da área evidenciará que não existe uma tipologia relacionada com género ou cultura, mas sim uma diversidade de pessoas com um interesse comum. Para esta tomada de consciência sobre a existência de estereótipos relacionados com a ciência e os cientistas, assumindo que entre eles essas representações não existem, pode ter contribuído a experiência da UJ, que incluiu o contacto com profissionais de diferentes géneros e culturas.

Questionados sobre a frequência de certas atividades de ocupação de tempos livres, os participantes destacaram programas de TV sobre o Espaço (Cosmos, por exemplo) e filmes sobre o Espaço (Interstellar e Perdido em Marte, por exemplo). Isto sugere que, apesar dos jovens não procurarem muito o jornalismo científico, outros conteúdos mediáticos de entretenimento e ficção têm uma forte adesão. Outras opções mais referidas nos questionários foram: "falar com alguém sobre o Espaço" e "descobrir mais sobre o Espaço na internet". Em discussão, os vídeo jogos sobre o Espaço foram criticados por alguns participantes como sendo irrealistas e mais de ficção científica do que de ciência. "Melhor são as simulações" (participante do sexo masculino, $10^{\circ}$ ano, grupo de discussão do questionário na semana 2).

$\mathrm{O}$ ato de "falar com alguém sobre o tema de Astronomia" foi discutido entre os jovens, que veem a semana na UJ como uma forma de partilhar o interesse que têm em comum. $\mathrm{Na}$ escola, com os amigos e professores, essa possibilidade não existe, pois não encontram com frequência pessoas que demonstrem interesse na Astronomia e consideram que falar com os professores pode ser mal-entendido pelos pares (como "graxa"). Partilhar informação de Astronomia na internet também "não vale a pena" (participante do sexo feminino, $11^{\circ}$ ano, grupo focal 4). Assim, a participação no evento é também uma forma de conhecer e dialogar com outros jovens interessados na área. Esta falta de interesse pela área que a maioria referenciou quando falava de amigos e familiares é atribuída à retirada dos conteúdos de Astronomia nas metas curriculares, o que - dizem - compromete o interesse geral das pessoas pelo tema.

Os participantes referiram também que a escola não os ensina a ler artigos científicos, nem a interpretar informação de ciência. Muitas vezes sentem a necessidade de melhor compreender o vocabulário usado na comunicação de ciência e que os cursos cientifico-tecnológicos não ensinam a comunicar, debater e apresentar resultados científicos. Aliás, sugerem que, tal como há Matemática Aplicada às Ciências Sociais para os cursos de secundário de Humanidades, também deveria haver Português Aplicado às Ciências, que englobasse estes aspetos que consideram cruciais para um futuro profissional na área das ciências. Este ponto é importante se considerarmos que um dos indicadores da literacia científica é justamente saber interpretar informação de ciência, como relatórios científicos veiculados nos media.

$\mathrm{Na}$ generalidade, os participantes foram muito críticos quanto à ausência da Astronomia e Ciências do Espaço em espaços formais de aprendizagem, sugerindo a realização de palestras e debates ou a participação em visitas de estudo e projetos como 
essenciais para a promoção desta área científica (e até de outros assuntos de interesse para outros alunos) na escola. Neste sentido, infere-se do discurso dos participantes que a escola falha na preparação de cidadãos, ao não diversificar as suas ofertas, nem agenciar os seus alunos para a participação e o diálogo em assuntos de ciência, nomeadamente com recurso aos media.

\section{Conclusões}

Uma conclusão interessante deste estudo foi a constatação de uma crítica quase unânime por parte dos participantes à ausência ou pouca expressividade do tema da Astronomia e Ciências do Espaço nos currículos escolares em Portugal. Não sendo a escola a promover o interesse nesta área, parece-nos evidente que as atividades de caráter informal assumem um papel importante na sua promoção. Livros, filmes, documentários e apresentações em diferentes formatos parecem ser preponderantes na definição de uma identidade relacionada com a ciência, o que destaca o papel das aprendizagens informais, nomeadamente nos media, nessa definição. Podemos inferir que estes consumos contribuem para a imagem e os conhecimentos de ciência que os mais novos vão construindo, contribuindo para a sua literacia científica (Tang, 2013; Tang \& Moje, 2010). Neste sentido, além de considerar a análise de notícias de relatórios científicos veiculados nos media como um indicador do nível de literacia dos estudantes (Korpan et al., 1997; Norris et al., 2003), analisar de forma crítica informação e representações de ciência nos diferentes tipos de media poderá ser um indicador mais robusto de uma literacia científica crítica.

Embora os participantes deste estudo façam referência a estereótipos existentes nas representações da ciência em sociedade (de género, de classe e de etnia, por exemplo), disseram estar imunes a eles, mostrando um certo grau de análise crítica que pode ser fruto da própria experiência vivida e do encontro com a diversidade de elementos da comunidade científica a trabalhar no CAUP. Apesar disso, quando se referiam a cientistas que seguiam nos media, apenas realçaram cientistas homens, numa discreta alusão a um papel masculino de autoridade, poder e credibilidade da ciência ainda prevalecente em diversos espaços, formais e informais, nomeadamente nos media (DeWitt \& Bultitude, 2018; Lane et al., 2012). Tomando este aspeto em consideração, parece-nos estar por explorar o potencial contributo dos media e das aprendizagens de ciência em contextos não formais para o desenvolvimento da literacia crítica de ciência, nomeadamente no questionamento de discursos sobre ciência e de representações dos cientistas nos media.

O que observamos parece contrariar a ideia de que os jovens não procuram informação de ciência. Apesar de não pesquisarem deliberadamente notícias de ciência em geral, encontrando-as antes de forma casual, os jovens seguem nas redes sociais páginas de instituições que vão de encontro aos seus interesses. Esses encontros casuais com notícias de ciência muitas vezes servem de mote para a pesquisa de informação complementar, impulsionada por interesses particulares. Os jovens entendem que esta 
atitude está relacionada com a procura de notícias de ciência, em momentos de lazer, quando estão a usar plataformas sociais, o que é condizente com o consumo de notícias em geral. Boczkowski et al. (2017) referem que o consumo de notícias pelos jovens surge de forma indiferenciada do resto da informação social e de entretenimento que surge nas redes sociais digitais, e avançam que esse consumo de forma casual está ligado ao acesso frequente à internet em dispositivos móveis, acedendo a informação várias vezes ao dia e em qualquer lugar, vendo apenas uma parte do conteúdo, normalmente de forma superficial. Esta forma superficial e casual pode justificar as parcas ou quase inexistentes atitudes de partilha ou de comentário relativamente às notícias, observadas também relativamente às notícias de ciência neste estudo.

A maioria dos participantes expressou uma identificação com áreas de ciências (nomeadamente Física e Astronomia) muitas vezes efetuada por oposição à área das letras e humanidades. Falas que incluíam referências ao "eles" e "nós" foram frequentes, levantando preocupações sobre a forma compartimentada como veem os processos de ciência, com poucas reflexões sobre outros contextos e ligações da ciência em sociedade, para além dos factos, conhecimentos ou aplicações de ciência. A ideia de que esta nos pode "salvar" e melhorar a vida das pessoas parece desconsiderar os constrangimentos dos processos e contextos sociais, económicos e financeiros em que a ciência é feita, aos quais os participantes parecem estar completamente alheios (exceção feita à questão do financiamento, que alguns referiram nos seus discursos).

Percebemos que os participantes estavam confortáveis como recetores de informação de ciência em espaços que consideraram de autoridade e credibilidade. Perspetivando-se que possam ser futuros cientistas, a iniciação a debates sobre como podem comunicar o seu próprio trabalho de ciência (nos media e noutros espaços) e como podem promover a participação democrática e governança da ciência (Lewenstein, 2015) numa relação dialógica entre esta e a sociedade poderia ser incentivada na escola e em contextos informais de comunicação de ciência. O desenvolvimento de competências enquanto não apenas consumidores, mas também como potenciais produtores de conteúdos poderia ser uma oportunidade para trabalhar em convergência as literacias críticas para a ciência e para os media.

\section{Agradecimentos}

Sara Anjos detém uma bolsa de investigação (SFRH/BD/123276/2016) cofinanciada pela FCT/FSE/MCTES através de fundos nacionais.

Este trabalho é financiado por fundos nacionais através da FCT - Fundação para a Ciência e a Tecnologia, I.P., no âmbito do projeto UIDB/00736/2020. O Financiamento Plurianual do Centro de Estudos de Comunicação e Sociedade (UIDB/o0736/2020) apoiou a revisão linguística da versão inglesa do artigo. 


\section{REFERÊNCIAS}

Bauer, M. W. (2008). Paradigm change for science communication: commercial science needs a critical public. In D. Cheng; M. Claessens; T. Gascoigne; J. Metcalfe; B. Schiele \& S. Shi (Eds.), Communicating science in social contexts (pp. 7-25). Dordrecht: Springer. https://doi.org/10.1007/978-1-4020-8598-7_1

Besley, J. C. \& Nisbet, M. (2013). How scientists view the public, the media and the political process. Public Understanding of Science, 22(6), 644-659. https://doi.org/10.1177/0963662511418743

Boczkowski, P. (2007). Bridging STS and communication studies: scholarship on media and information technologies. In U. Felt, R. Fouché, C. A. Miller \& L. Smith-Doerr (Eds.), The Handbook of Science and Technology Studies (pp. 949-977). Cambridge: MIT Press.

Boczkowski, P., Mitchelstein, E. \& Matassi, M. (2017). Incidental news: how young people consume news on social media. In T. X. Bui \& R. Sprague (Eds.), Proceedings of the 50 th Hawaii International Conference on System Sciences (pp. 1785-1792). https://doi.org/10.24251/HICSS.2017.217

Brossard, D. \& Scheufele, D. A. (2013). Science, new media, and the public. Science, 339(6115), 40-41. https:// doi.org/10.1126/science.1232329

Bubela, T., et al. (2009). Science communication reconsidered. Nature Biotechnology, 27, 514-518. https://doi. org/10.1038/nbto6og-514

Bucchi, M. \& Trench, B. (2014). Science communication research. In M. Bucchi \& B. Trench (Eds.), Routledge handbook of public communication of Science and Technology (pp. 1-14). Londres: Routledge. https://doi. org/10.4324/9780203483794.ch1

Buckingham, D. (2008). Introducing identity. In D. Buckingham (Ed.), Youth, identity, and digital media (pp. 1-22). Cambridge, MA: The MIT Press.

Buckingham, D., Banaji, S., Carr, D., Cranmer, S. \& Willett, R. (2005). The media literacy of children and young people: a review of the research literature. Londres: Ofcom

Cardoso, G., Mendonça, S., Paisana, M. \& Lima, T. (2016). Perfil sociodemográfico do consumo de notícias em Portugal. Lisboa: Obercom.

Carvalho, A. (2004). Política, cidadania e comunicação 'crítica' da ciência. Comunicação e Sociedade, 6, 35-49. https://doi.org/10.17231/comsoc.6(2004).1227

Cope, B. \& Kalantzis, M. (2009). "Multiliteracies": new literacies, new learning. Pedagogies: An International Journal, 4(3), 164-195.

Davies, S. R. \& Horst, M. (2016). Science communication: culture, identity and citizenship. Londres: Palgrave Macmillan.

DeBoer, G. E. (2000). Scientific literacy: another look at its historical and contemporary meanings and its relationship to science education reform. Journal of Research in Science Teaching, 37(6), 582-601.

DeWitt, J. \& Bultitude, K. (2018). Space Science: the view from european school students. Research in Science Education. https://doi.org/10.1007/s11165-018-9759-y

DeWitt, J., Osborne, J., Archer, L., Dillon, J., Willis, B. \& Wong, B. (2013). Young children's aspirations in science: the unequivocal, the uncertain and the unthinkable. International Journal of Science Education, 35(6), 1037-1063. https://doi.org/10.1080/09500693.2011.608197 
Dover, C. (2007). Everyday talk: investigating media consumption and identity amongst school children. Participations, 4(1). Retirado de http://www.participations.org/Volume\%204/Issue\%201/4_01_dover. htm

Entradas, M. (2015). Envolvimento societal pelos centros de I\&D. In M. d. L. Rodrigues \& M. Heitor (Eds.), 40 anos de políticas de Ciência e de Ensino Superior (pp. 503-518). Coimbra: Almedina.

Falk, J. H., Storksdieck, M. \& Dierking, L. D. (2007). Investigating public science interest and understanding: evidence for the importance of free-choice learning. Public Understanding of Science, 16(4), 455-469. https://doi.org/10.1177/0963662506064240

Feinstein, N. (2011). Salvaging science literacy. Science Education, 95(1), 168-185. https://doi.org/10.1002/ sce.20414

Feinstein, N. W. (2015). Education, communication, and science in the public sphere. Journal of Research in Science Teaching, 52(2), 145-163. https://doi.org/10.1002/tea.21192

Gainer, J. S. (2010). Critical media literacy in middle school: exploring the politics of representation. Journal of Adolescent Q Adult Literacy, 53(5), 364-373. https://doi.org/10.1598/JAAL.53.5.2

Gerhards, J. \& Schäfer, M. S. (2009). Two normative models of science in the public sphere: human genome sequencing in German and US mass media. Public Understanding of Science, 18(4), 437-451. https://doi. org/10.1177/0963662507082891

Gregory, A. \& Cahill, M. A. (2009). Constructing critical literacy: self-reflexive ways for curriculum and pedagogy. Critical Literacy: Theories and Practices, 3(2), 6-16.

Halkia, K. \& Mantzouridis, D. (2005). Students' views and attitudes towards the communication code used in press articles about science. International Journal of Science Education, 27(12), 1395-1411. https://doi. org/10.1080/09500690500102912

Hofstein, A., Eilks, I. \& Bybee, R. (2011). Societal issues and their importance for contemporary science education - a pedagogical justification and the state-of-the-art in Israel, Germany, and the USA. International Journal of Science and Mathematics Education, 9(6), 1459-1483.

Jarman, R. \& McClune, B. (2010). Developing students' ability to engage critically with science in the news: Identifying elements of the 'media awareness' dimension. The Curriculum Journal, 21(1), 47-64. https:// doi.org/10.1080/09585170903558380

Kellner, D. \& Share, J. (2007). Critical media literacy, democracy, and the reconstruction of education. In D. Macedo \& S. R. Steinberg (Eds.), Media literacy: a reader (pp. 3-23). Nova lorque: Peter Lang Publishing.

Korpan, C. A., Bisanz, G. L., Bisanz, J. \& Henderson, J. M. (1997). Assessing literacy in science: evaluation of scientific news briefs. Science Education, 81(5), 515-532. https://doi.org/10.1002/ (SICI) 1098-237X(199709)81:5<515::AID-SCE2>3.0.CO;2-D

Lane, K. A., Goh, J. X. \& Driver-Linn, E. (2012). Implicit science stereotypes mediate the relationship between gender and academic participation. Sex Roles, 66(3), 220-234. https://doi.org/10.1007/ s11199-011-0036-z

Lewenstein, B. V. (2015). Identifying what matters: science education, science communication, and democracy. Journal of Research in Science Teaching, 52(2), 253-262. https://doi.org/10.1002/tea.21201

Mendick, H. \& Moreau, M.-P. (2013). New media, old images: constructing online representations of women and men in science, engineering and technology. Gender and Education, 25(3), 325-339. https://doi.org/1 o.1080/09540253.2012.740447 
Miller, D. I., Eagly, A. H. \& Linn, M. C. (2015). Women's representation in science predicts national genderscience stereotypes: evidence from 66 nations. Journal of Educational Psychology, 107(3), 631-644. https://doi.org/10.1037/eduoooooo5

Nelms, C., Allen, M. W., Craig, C. A. \& Riggs, S. (2017). Who is the adolescent environmentalist? Environmental attitudes, identity, media usage and communication orientation. Environmental Communication, 11(4), 537-553. https://doi.org/10.1080/17524032.2016.1275733

Norris, S. P., Phillips, L. M. \& Korpan, C. A. (2003). University students' interpretation of media reports of science and its relationship to background knowledge, interest, and reading difficulty. Public Understanding of Science, 12(2), 123-145. https://doi.org/10.1177/09636625030122001

Pereira, S., Fillol, J. \& Moura, P. (2019). Young people learning from digital media outside of school: the informal meets the formal. Comunicar, 27(58), 41-50. https://doi.org/10.3916/C58-2019-04

Peters, H. P., Brossard, D., de Cheveigne, S., Dunwoody, S., Kallfass, M., Miller, S. \& Tsuchida, S. (2008). Interactions with the mass media. Science, 321 (5886), 204-205. https://doi.org/10.1126/science.1157780

Priest, S. (2013). Critical science literacy: what citizens and journalists need to know to make sense of science. Bulletin of Science, Technology \& Society, 33(5-6), 138-145. https://doi.org/10.1177/0270467614529707

Rahim, S. A. \& Pawanteh, L. (2009). Media penetration and cultural identity among young adults in Malaysia. European Journal of Social Sciences, 11(2), 225-233.

Suerdem, A., Bauer, M. W., Howard, S. \& Ruby, L. (2013). PUS in turbulent times II - a shifting vocabulary that brokers inter-disciplinary knowledge. Public Understanding of Science, 22(1), 2-15. https://doi. org/10.1177/0963662512471911

Tang, K.-S. (2013). Out-of-school media representations of science and technology and their relevance for engineering learning. Journal of Engineering Education, 102(1), 51-76. https://doi.org/10.1002/jee.20007

Tang, K.-S. \& Moje, E. B. (2010). Relating multimodal representations to the literacies of science. Research in Science Education, 40(1), 81-85. https://doi.org/10.1007/s11165-009-9158-5

Tőrők-Ágoston, R. (2017). Education and social media. Journal of Media Research, 10(2 [28]), 166-184. https:// doi.org/10.24193/jmr.28.12

\section{NotAS BIOGRÁFICAS}

Sara Anjos é aluna de doutoramento na Universidade do Minho e na Universidade de Leiden. A sua investigação centra-se em Estudos de Ciência, Tecnologia e Sociedade, particularmente no envolvimento do público jovem com a Astronomia. É licenciada em Astronomia, tem um Mestrado em Ciências da Educação e um MBA. É membro de vários grupos de investigação em Ciência, Comunicação e Educação e foi coordenadora do Gabinete da Língua Portuguesa de Astronomia para o Desenvolvimento (PLOAD-IAU) até 2017.

ORCID: https://orcid.org/o000-0002-8544-7471

Email: saraanjos@gmail.com

Morada: Universidade do Minho, Campus de Gualtar, 4710-057 Braga, Portugal; Leiden University, Sylvius, Sylviusweg 72, 2333 BE Leiden 
Anabela Carvalho (PhD, University College - Londres) é Professora Associada do Departamento de Ciências da Comunicação da Universidade do Minho, em Portugal. Desenvolve investigação sobre as diversas formas de ambiente, comunicação de ciência e política, com foco particular nas alterações climáticas. Publicou diversos livros, entre eles Communicating climate change: discourses, mediations and perceptions (2008), Citizen voices: enacting public participation in science and environment communication (com L. Phillips e J. Doyle; 2012), Climate change politics: communication and public engagement (com T. R. Peterson; 2012). Atualmente é diretora do Doutoramento em Estudos de Comunicação: Tecnologia, Cultura e Sociedade.

ORCID: https://orcid.org/oooo-0o02-7727-4187

Email: carvalho@ics.uminho.pt

Morada: Universidade do Minho, Campus de Gualtar, 4710-057 Braga, Portugal

* Submissão: 23/12/2019

* Aceitação: 14/04/2020 